\title{
Numeric Simulation for the Seabed Deformation in the Process of Gas Hydrate Dissociated by Depressurization
}

\author{
Zhenwei Zhao ${ }^{1,3}$ and Xinchun Shang ${ }^{2}$ \\ ${ }^{1}$ Department of Civil Engineering, University of Science and Technology Beijing, \\ Beijing, China \\ ${ }^{2}$ Department of mathematics and Mechanics, University of Science and Technology Beijing, \\ Beijing, China \\ ${ }^{3}$ Institute of Mechanics, Chinese Academy of Sciences, Beijing, China \\ Zhaozhenwei1979@sohu.com, \\ sxc1958@126. com
}

\begin{abstract}
When the gas hydrates dissociate, the mechanical properties of sediments will change, which may cause the deformation of the seabed. Such incidence will directly affect the stability of the undersea device. Under the consideration of seepage-stress coupling, this paper analyzed the deformation of seabed using finite element method. Duncan Chang's E-B constitutive model code was written, the impact of stress on the elastic constants was considered in this model. It was implemented in ABAQUS and used to simulating the nonlinear deformation of sediments. The results show that vertical effective stress of soil around the well increase significantly when gas hydrates are exploited by depressurization. The deformation of seabed increases nonlinearly with the increasing of the decomposition radius of hydrate. The maximum settlement reaches $9 \mathrm{~m}$ and the maximum horizontal displacement reaches $4 \mathrm{~m}$. The results provide guidance on the submarine construction in the process of gas production from hydrates.
\end{abstract}

Keywords: Gas hydrates; Redevelopment of ABAQUS; Seabed deformation.

\section{Introduction}

Gas hydrates are solid crystalline compounds in which gas molecules are lodged within the lattices of ice crystals under conditions of low temperature and high pressure [1]. Vast amounts of $\mathrm{CH}_{4}$ are trapped in naturally occurring hydrate accumulations in the permafrost and in deep ocean sediments [2]. One volume of natural gas hydrates contains about 164 volumes of $\mathrm{CH}_{4}$ [3]. The amount of hydrocarbons residing in hydrate deposits is estimated to substantially exceed all known conventional oil and gas resources.

The reduction of pore pressure and the decreases of soil strength due to the loss of hydrates will cause the deformation of seabed; it will affect the stability of submarine facilities. Jeonghwan Lee et al. gave an experimental study on the gas production from hydrate by depressurization, it was shown that the degree of depressurization has 
significant influence on the gas production rate, but the filed of stress was not studied [4]. S. Y. Wang et al. analyzed the effect of gas hydrates decomposition on the pipeline stability and the deformation of soil using finite element method, but the change of pressure was neglected in their research [5]. M. Y. A. Ng et al. studied the deformation of soil around the wellbore, the elastic-plastic model was used in their research [6]. Sayuri Kimoto et al. analyzed the deformation of ground induced by hydrate dissociation, Elastic-viscoplastic model was used to simulate the deformation of soil [7]. In this study, FORTRAN language was used to actuating the secondary development of ABAQUS finite element software. Duncan Chang's E-B constitutive model code was written here, combined with Biot's consolidation theory; it was used to simulating the nonlinear deformation of seabed.

\section{Calculation Principle}

\subsection{Biot's Consolidation Theory}

Biot's consolidation equations are derived by static equilibrium equations and continuous flow equations, it is tiger in theory and can be used to solve the deformation of soil and the pore pressure combined with the constitutive model of soil. It is based on the small deformation assumption and linear elastic constitutive model, the seepage obeys Darcy's law, soil particles and water can not be compressed. Soil skeleton satisfy the following basic equilibrium equations [8]:

$$
\begin{gathered}
\frac{\partial \sigma_{x}}{\partial x}+\frac{\partial \tau_{y x}}{\partial y}+\frac{\partial \tau_{z x}}{\partial z}+\frac{\partial P}{\partial x}=0 . \\
\frac{\partial \tau_{x y}}{\partial x}+\frac{\partial \sigma_{y}}{\partial y}+\frac{\partial \tau_{z y}}{\partial z}+\frac{\partial P}{\partial y}=0 . \\
\frac{\partial \tau_{x z}}{\partial x}+\frac{\partial \tau_{y z}}{\partial y}+\frac{\partial \sigma_{z}}{\partial z}+\frac{\partial P}{\partial y}+\rho g=0 .
\end{gathered}
$$

Where, $\rho$ is the saturation density of soil, $\sigma, \tau$ are effective stress, $\mathrm{P}$ is the pressure of water.

It is assumed that the seepage obey Darcy's law, based on the compatibility equations of soil and the continuity principle of water, the relationship between the displacement and pore pressure can be derived as follows:

$$
\frac{\partial}{\partial t}\left(\frac{\partial u}{\partial x}+\frac{\partial v}{\partial y}+\frac{\partial w}{\partial z}\right)-\frac{k}{\rho_{w} g}\left(\frac{\partial^{2} P}{\partial x^{2}}+\frac{\partial^{2} P}{\partial y^{2}}+\frac{\partial^{2} P}{\partial z^{2}}\right)=0 .
$$

Where $\mathrm{k}$ is the permeability coefficient of soil, $\mathrm{u}, \mathrm{v}, \mathrm{w}$ is the displacement of soil, $\rho_{\mathrm{w}}$ is the density of water.

The stress can be expressed by the deformation of displacement using the constitutive equation and the geometric equation, thus displacement $\mathrm{u}, \mathrm{v}, \mathrm{w}$ and pore water pressure $\mathrm{P}$ can be solved by (1)-(4). 


\subsection{Nonlinear Constitutive Model of Soil}

The nonlinear deformation of the soil can be analyzed using finite element method by updating the elastic constants in each incremental step. Duncan-Chang model is a nonlinear elastic model based on the relationship between stress increment and strain increment, elastic constants change in different incremental step, but the relationship between stress and strain satisfies Hooke's Law in each step increment. Because Duncan-Chang model can simulate the nonlinear deformation of soil accurately, it is widely used in engineering. The elastic constants in Duncan Chang's E-B model are calculated as follows [8]:

$$
\begin{gathered}
E_{t}=K_{a} p_{a}\left(\frac{\sigma_{3}}{p_{a}}\right)^{n}\left[1-\frac{R_{f}\left(\sigma_{1}-\sigma_{3}\right)(1-\sin \phi)}{2 c \cos \phi}\right]^{2} . \\
B=k_{b} p_{a}\left(\frac{\sigma_{3}}{p_{a}}\right)^{m} .
\end{gathered}
$$

Where $\mathrm{Ka}, \mathrm{n}, \mathrm{R}_{\mathrm{f}}, \mathrm{c}, \Phi, \mathrm{K}_{\mathrm{b}}$ and $\mathrm{m}$ are material constants.

\section{Finite Element Analysis}

\subsection{Calculation Model}

Gas hydrates exists in the pore of clay at 191-225 m below the seabed in South China Sea, the water depth is $1230 \mathrm{~m}$. It is assumed that there is a horizontal well in the center of hydrate layer, gas hydrates are decomposed by depressurization. The problem can be reduced to a plane strain problem. The finite element model is created considering a longitudinal section (see Fig.1), $3000 \mathrm{~m}$ is taken in horizontal direction, $r_{c}$ is the decomposition radius.

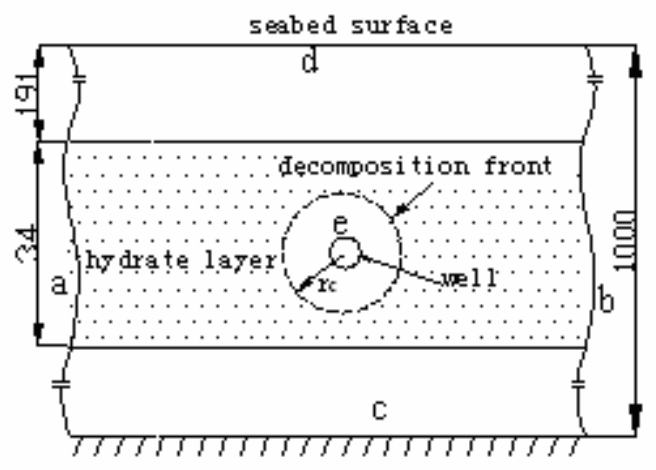

Fig. 1. The sketch for the finite element model 


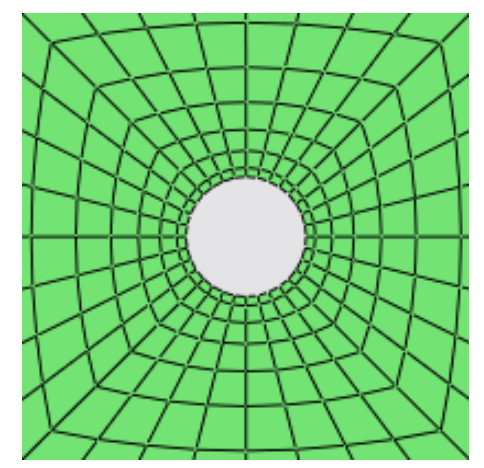

Fig. 2. The mesh in local region around the well

\subsection{Computation Parameters}

The mechanical parameters of sediment change significantly after gas hydrates dissociate, the parameters need to be adjusted in the process of calculation. Duncan Chang's E-B subroutine is used here to define the mechanical constitutive behavior of soil. The change of the parameters due to the loss of hydrates can be achieved by using User Defined Field subroutine. User Defined Field subroutine can define field variables and it can be used in conjunction with Duncan Chang's E-B model subroutine. The value of pore water pressure can be extracted by User Defined Field subroutine, the parameters are defined as a function of pore pressure, and they are updated according to the value of pore water pressure in each increment. At a certain temperature, hydrates will dissociate while the pressure decreases below the equilibrium pressure $\mathrm{P}_{\mathrm{e}}$, the sediment parameters will change at this time. The equilibrium pressure $\mathrm{P}_{\mathrm{e}}$ can be calculated by the following phase equilibrium equation [9]:

$$
\log _{10} \mathrm{P}_{\mathrm{e}}=\mathrm{aT}+\mathrm{bT}^{2}+\mathrm{c},
$$

where $\mathrm{T}$ is the temperature of sediment, $\mathrm{a}=0.0342 \mathrm{~K}^{-1}, \mathrm{~b}=0.0005 \mathrm{~K}^{-1}, \mathrm{c}=6.4804$. The parameters are obtained from experiment data in [10] and [11], Duncan-Chang model parameters are shown in Table 1.

Table 1. Parameters in Duncan Chang's $E-B$ model

\begin{tabular}{c|ccccc}
\hline Depth (m) & $0-50$ & $50-191$ & $\begin{array}{c}191-225 \\
\left(\mathrm{P}>\mathrm{P}_{\mathrm{e}}\right)\end{array}$ & $\begin{array}{c}191-225 \\
\left(\mathrm{P}<\mathrm{P}_{\mathrm{e}}\right)\end{array}$ & $225-500$ \\
\hline $\mathrm{k}_{\mathrm{a}}$ & 29.7 & 108 & 223 & 40.1 & 178 \\
$\mathrm{n}$ & 0.35 & 0.35 & 0.35 & 0.35 & 0.35 \\
$\mathrm{R}_{\mathrm{f}}$ & 0.78 & 0.78 & 0.78 & 0.78 & 0.78 \\
$\mathrm{C}(\mathrm{kpa})$ & 14 & 44 & 59 & 25.6 & 54 \\
$\Phi$ & 10 & 20 & 22 & 12.1 & 21 \\
$\mathrm{~K}_{\mathrm{b}}$ & 24.8 & 90.75 & 185.6 & 33.4 & 148.8 \\
$\mathrm{M}$ & 0.45 & 0.45 & 0.45 & 0.45 & 0.45 \\
\hline $\mathrm{k}_{\mathrm{ur}}$ & 1.2 & 1.2 & 1.2 & 1.2 & 1.2 \\
\hline
\end{tabular}




\section{The Results and Analysis}

When the gas hydrates are decomposed by depressurization, the pore water pressure field tends to be stable after a period of time, the hydrate dissociation front doesn't move forward any more, the decomposition radius becomes $55 \mathrm{~m}$ finally.

Fig. 3 shows the distribution of pore water pressure when $r_{c}$ gets $55 \mathrm{~m}$. Pore water pressure decreases obviously only in the area just around the well, The reduction of pressure will result in the redistribution of the stress of soil.

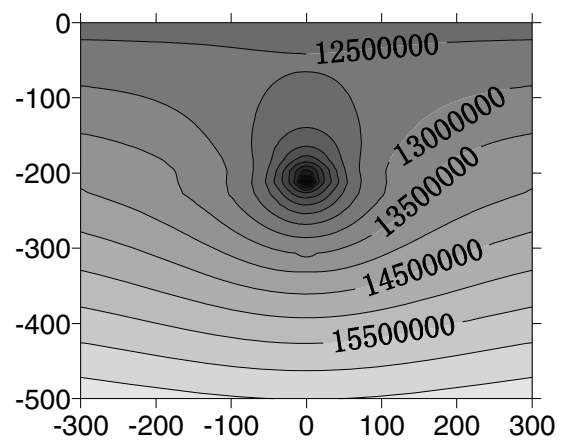

Fig. 3. The distribution of pore pressure

The distribution of vertical effective stress is shown in Fig.4. The vertical effective stress of soil increase significantly just around the well mainly because of the depressurization, and the force acting on the pipe will increase accordingly. The vertical effective stress of soil in the area near the surface of the seabed doesn't change evidently.

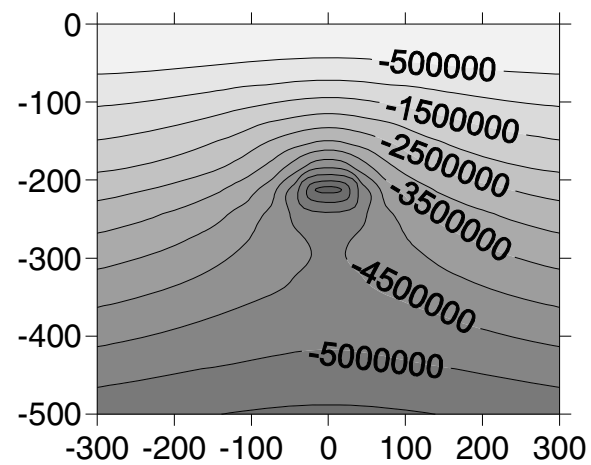

Fig. 4. The distribution of vertical effective stress

The reduction of sediment elastic constants due to the loss of hydrates and the increase of effective stress of soil will result in the deformation of soil. Fig.5 shows the settlement of soil while $r_{c}$ reaches $55 \mathrm{~m}$. The largest settlement occurs in the seabed surface directly above the well, it reaches $9 \mathrm{~m}$. The settlement decreases 
gradually to the periphery; it indicates there isn't significant dislocation. Fig.6 shows the horizontal displacement of soil while $r_{c}$ gets $55 \mathrm{~m}$, the largest horizontal displacement occurs in the seabed surface $280 \mathrm{~m}$ from the center, it reaches $4 \mathrm{~m}$.

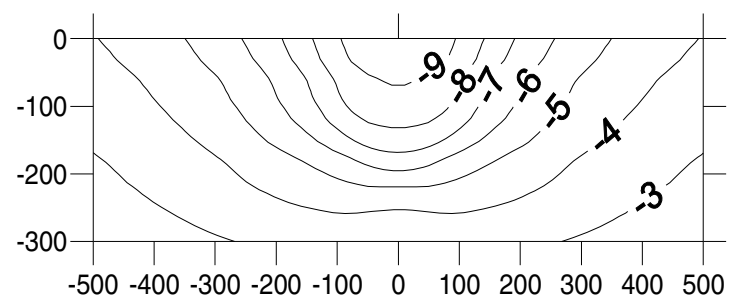

Fig. 5. The distribution of vertical displacement

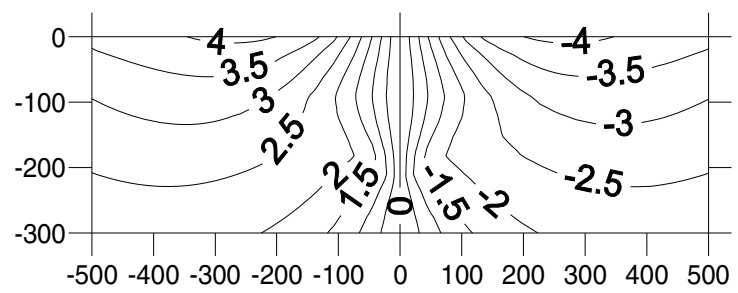

Fig. 6. The distribution of horizontal displacement

The deformation of the seabed surface has a direct effect on the stability of submarine facilities. The distribution of the displacement of seabed surface and its variations with $r_{c}$ are discussed as below. Fig.7 shows the settlement of seabed surface while $r_{c}$ reaches $10 \mathrm{~m}, 20 \mathrm{~m}, 30 \mathrm{~m}, 40 \mathrm{~m}, 50 \mathrm{~m}$ respectively. The settlement is larger in the area that horizontal coordinate is less than 200 meters. It is can be seen from Fig.7, the decomposition radius of gas hydrate has significant impact on the settlement of the seabed surface. When $r_{c}$ is less than $20 \mathrm{~m}$, the largest settlement is about $0.8 \mathrm{~m}$.Largest settlement increase nonlinearly with the increasing of $r_{c}$, especially when $r_{c}$ increases from $40 \mathrm{~m}$ to $55 \mathrm{~m}$, the largest settlement changes from $5 \mathrm{~m}$ to $10 \mathrm{~m}$.

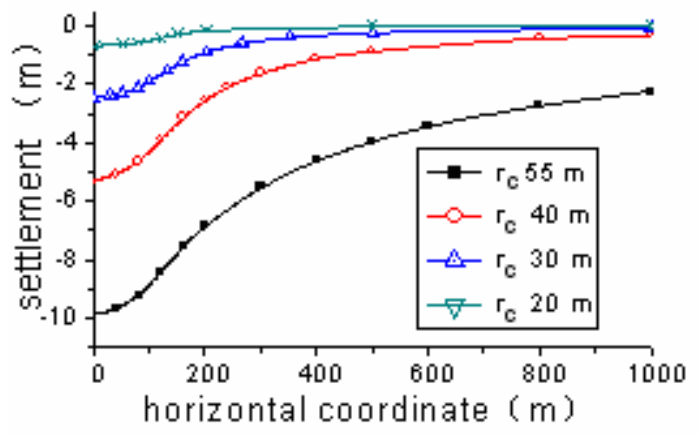

Fig. 7. The settlement of seabed surface corresponding to different decomposition radius 
Fig. 8 shows the horizontal displacement of seabed surface while $r_{c}$ reaches $10 \mathrm{~m}, 20$ $\mathrm{m}, 30 \mathrm{~m}, 40 \mathrm{~m}, 50 \mathrm{~m}$ respectively. Coordinate of the location that the maximum horizontal displacement occurs changes with the increasing of $r_{c}$. When $r_{c}$ increases from $20 \mathrm{~m}$ to $55 \mathrm{~m}$, it changes from 180 to $250 \mathrm{~m}$. The maximum horizontal displacement is affected significantly by the decomposition radius of gas hydrates, it increases with the increasing of $r_{c}$, the maximum horizontal reaches $4 \mathrm{~m}$ while $r_{c}$ gets $55 \mathrm{~m}$.

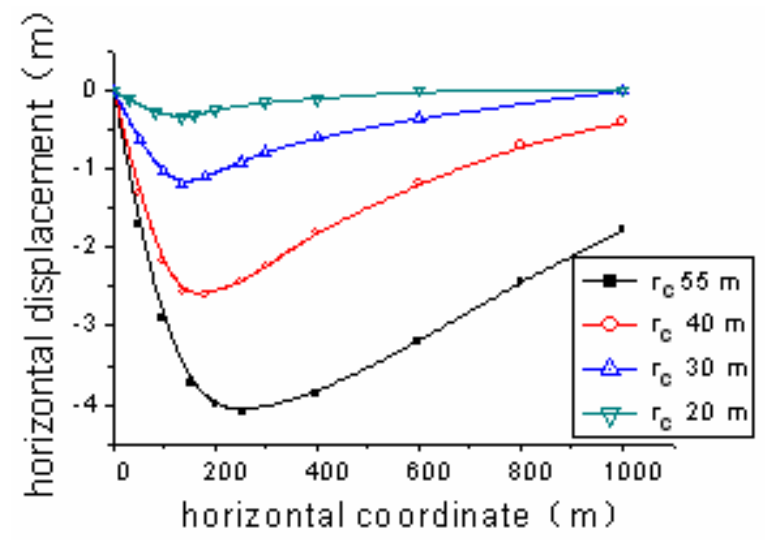

Fig. 8. The horizontal displacement of seabed surface corresponding to different decomposition radius

\section{Conclusions}

From the results of the coupling analysis on seepage and stress fields in the process of gas production from hydrates, the conclusions are obtained as follows:

(1) If gas hydrates are exploited by drilling horizontal well, the maximum settlement and horizontal displacement occurs in the seabed surface, they reach $9 \mathrm{~m}$ and $4 \mathrm{~m}$ respectively. The sea floor facility should be distributed symmetrically around the well in order to avoid inclination, and it should not be constructed in the location that maximum horizontal displacement occurs.

(2) The settlement and horizontal displacement of the seabed surface increase nonlinearly with the increasing of decomposition radius. In order to reduce the disaster of deformation of the soil, the decomposition range of gas hydrate should be controlled appropriately.

(3) The vertical effective stress of soil increase significantly around the well due to the reduction of pore pressure, it has potential impact on the stability of submarine pipeline. The results provide reference for the design of submarine pipeline.

\section{References}

1. Kowalsky, M.B., Moridis, G.J.: Comparison of Kinetic and Equilibrium Reaction Models in Simulating Gas Hydrate Behavior in Porous Media. Energy Conversion and Management 48, 1850-1863 (2007) 
2. Alp, D., Parlaktuna, M., Moridis, G.J.: Gas Production by Depressurization from Hypothetical Class $1 \mathrm{G}$ and Class $1 \mathrm{~W}$ Hydrate Reservoirs. Energy Conversion and Management 48, 1864-1879 (2007)

3. Liu, Y., Strumendo, M., Arastoopour, H.: Simulation of Methane Production from Hydrates by Depressurization and Thermal Stimulation. Ind. Eng. Chem. Res. 48, 2451-2464 (2009)

4. Lee, J., Park, S., Sung, W.: An Experimental Study on the Productivity of Dissociated Gas from Gas hydrate by Depressurization scheme. Energy Conversion and Management (2010)

5. Shuyun, W., Li, W., Xiaobing, L., Qingping, L.: Numerical Analysis of the Effects of Gas Hydrate Dissociation on the Stability of Deposits and Pipes. China Offshore Oil and Gas 20, 127-131 (2008)

6. Ng, M.Y.A., Klar, A.: Coupled Soil Deformation-Flow-Thermal Analysis of Methane Production in Layered Methane Hydrate Soils. In: Offshore Technology Conference, Houston, pp. 1258-1270 (2008)

7. Kimoto, S., Oka, F., Fushita, T.: A Chemo-thermo-mechanically Coupled Analysis of Ground Deformation Induced by Gas Hydrate Dissociation. International Journal of Mechanical Science 52, 365-376 (2010)

8. Guangxin, L.: Advanced Soil Mechanics. Tsing-hua University press, Beijing (2004)

9. Ahmadi, G., Ji, C., Smith, D.H.: Production of Natural Gas from Methane Hydrate by a Constant Downhole Pressure Well. Energy Conversion and Management 48, 2053-2068 (2007)

10. Sanyuan, S., Qun, L., Deqian, L.: Study on Parameters of Duncan-Chang Model for Handan Silt Clay. Journal of Hebei Institute of Architectural Science and Technology 23, $1-3$ (2006)

11. Masui, A., Haneda, H., Ogata, Y., Aoki, K.: Effects of Methane Hydrate Formation on Shear Strength of Synthetic Methane Hydrate Sediments. In: Proceedings of the Fifteenth International Offshore and Polar Engineering Conference, Seoul, pp. 364-369 (2005) 